\title{
Units for Vital Signs Results
}

National Cancer Institute

\section{Source}

National Cancer Institute. Units for Vital Signs Results. NCI Thesaurus. Code C49675.

The unit used to record and describe the result of a test investigating a vital sign. 